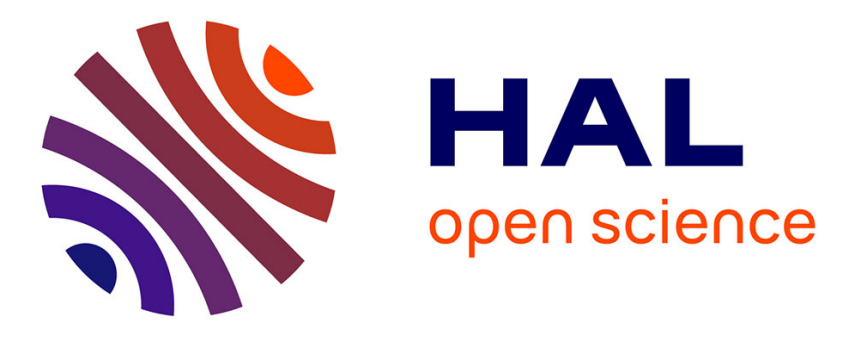

\title{
Applicability of ERP for Production Network Planning: A Case Study
}

\author{
Taravatsadat Nehzati, Anita Romsdal, Heidi Carin Dreyer, Jan Ola \\ Strandhagen
}

\section{- To cite this version:}

Taravatsadat Nehzati, Anita Romsdal, Heidi Carin Dreyer, Jan Ola Strandhagen. Applicability of ERP for Production Network Planning: A Case Study. IFIP International Conference on Advances in Production Management Systems (APMS), Sep 2014, Ajaccio, France. pp.580-588, 10.1007/9783-662-44739-0_71 . hal-01388600

\section{HAL Id: hal-01388600 \\ https://hal.inria.fr/hal-01388600}

Submitted on 27 Oct 2016

HAL is a multi-disciplinary open access archive for the deposit and dissemination of scientific research documents, whether they are published or not. The documents may come from teaching and research institutions in France or abroad, or from public or private research centers.
L'archive ouverte pluridisciplinaire HAL, est destinée au dépôt et à la diffusion de documents scientifiques de niveau recherche, publiés ou non, émanant des établissements d'enseignement et de recherche français ou étrangers, des laboratoires publics ou privés. 


\title{
Applicability of ERP for Production Network Planning: A Case Study
}

\author{
Taravatsadat Nehzati; Anita Romsdal; Heidi C. Dreyer; Jan Ola Strandhagen \\ taravatsadat.nehzati@ntnu.no, anita.romsdalentnu.no, \\ heidi.c.dreyer@ntnu.no, ola.strandhagen@ntnu.no \\ Department of Production and Quality engineering, Faculty of Engineering science and Technology, \\ Norwegian University of Science and Technology, 7491 Trondheim, Norway
}

\begin{abstract}
A production network enables a company to develop capabilities to respond to diversity in national or regional demand, while at the same time integrate and coordinate their activities. Many companies have implemented enterprise resource planning (ERP) systems to overcome problems associated with coordination and planning in an organization, in recent years. In addition, advanced planning and scheduling (APS) systems have emerged to address the planning insufficiencies of ERP systems. However, due to complexity and competence dependency of these systems, advantages of them are overlooked by large organizations, and therefore ERP systems are still in use for planning. ERP systems are used in production networks for coordination of various plans and decisions across network partners. This paper aims to assess the fit and alignment between ERP functions and production network requirement for supporting production planning processes. Using a case study approach, the paper illustrates and discusses the applicability of ERP systems for planning in production networks. The case study showed that ERP systems have limited ability in coordinating order allocation in the network, detailed short term production planning and inter network distributions. It is concluded that use of ERP systems for network planning may in fact limit the network's ability to reap the full benefits associated with planning across several facilities in a network.
\end{abstract}

Keywords: Production planning, Production network, Enterprise resource planning, ERP system

\section{$1 \quad$ Introduction}

Dynamic and unstable consumer markets require more agility in manufacturing companies [1]. Keeping proximity to customers to reduce response times to changes in demand has been a motivation for companies to spread the production sites geographically or to find industrial partners to cooperate with. This motivates the formation of production networks. Göttlich, Herty [2] defined production networks as "a set of processes utilized to efficiently integrate suppliers, manufacturers, and customers so that goods are produced and distributed in the right quantities, to the right location". A production network enables a company to develop capabilities to respond to diversity in national or regional demand, while at the same time integrate and coordinate their activities to reduce costs and improve productivity. Parameters like speed, flexibility, productivity and cost are improved, but the need for integration and coordination of processes and information are increased drastically [3].

Many companies have implemented an Enterprise Resource Planning (ERP) system to support their internal processes. New requirements for collaboration across facility borders have led to increased demand for different functionalities in the enterprise software, such as high degree of adaptability to diverse conditions, a concise provision of comprehensive

adfa, p. 1, 2011.

(C) Springer-Verlag Berlin Heidelberg 2011 
information, the capability to be applied across facilities in the network and good capabilities to support key planning processes. In order to fully exploit the advantages of the network setting, supportive information system should be capable of meeting the mentioned production network needs. ERP systems are designed to provide business benefits such as data visibility and task automation, particularly for large enterprises. ERP systems are therefore still the backbone of most companies' production planning processes. However, it has been argued that ERP systems are ill-equipped for planning in certain environments $[4,5]$. The fact that ERP systems are applied to support planning in production networks motivated us to study in more detail the particular challenges and limitations these practices impose on production planning for production networks.

The paper is structured as follows: in section 2 we explain about methodology used in this paper, section 3 briefly presents the production network concept and production planning processes in a network perspective. Section 4 focuses on the case study, describing production network characteristics and discussing how production planning tasks are executed through the use of an ERP system. Section 5 analyzes data from case study before Section 5 presents some conclusion and suggestions for further research.

\section{$2 \quad$ Methodology}

A case study is used to provide a better understanding of the applicability of ERP to support production planning in production network and to understand the practical limitations and challenges. Case studies are known as a strong means for conducting descriptive research and help to gain insights into areas that have not been explored in the literature [6]. This study focuses on the production network of one company and studies the consequences of applying an ERP system for managing production planning processes. Data was collected through semi-formal interviews with central and local planners. Explanation building is used as analytic technique for analyzing the case study data [6]. Using this method of analysis we will explain the link between phenomena and reason(s) behind that, which may be complex and difficult to measure in precise manner. After analysis, the results were discussed with other researchers and verified with key resources in the case company's supply chain department.

\section{$3 \quad$ Planning in production networks}

A production network consists of manufacturing plants that cooperate and share resources with each other. To describe type of production network, different elements need to be considered. Rudberg and Olhager [7] classified types of production networks based on number of organizations in the network and number of sites in each organization. For example multiple organization in the network and single site per organization is defined as supply chain while single organization and multiple sites in that organization is described as intrafirm network. Thus, they define different types of network based on number of organization/sites involved in composition. Phillis, D'Angelo [8], on the other hand, had specific focus on configuration of the production network. They stated that plants in production network may connect to each other in series (sequential), in parallel, or in series-parallel, where in parallel networks, all stations/plants operate in the same level of value adding and can work independent to each other, while plants/works stations in serial (sequential) networks need to work at the same rate and each facility is proceeded or succeeded only by one facility [9]. 
Beside organizational characteristics, which may affect collaboration in production network, the applied control principle plays a significant role in planning for production network, as it to a large extent determines the flow of goods in the network. Wiendahl and Lutz (2002) have listed three control principles from literature, known as; centralized, decentralized and loadoriented control [9]. With having several plants in the production network, one of the key logistical challenges will be to coordinate deliveries and production plan accordingly. Therefore having an effective control principle for the network can be a challenge. In addition, Scholz-Reiter, Dashkowskiy [10] have listed scheduling of shop floor and planning [11] (Where to produce what?) of transport operations [12] (optimize intra network transportation), as other two planning problems in production network.

Information systems are used widely for supporting coordination in production networks. Sheu, Chae [13], focused on ERP application in multisite firms, and highlights the complexity of module integration among facilities. Jacobs and Whybark [14] and Markus, Tanis [15] believe that implementation of ERP system in production networks can end up in failure unless differences production methods and customer demand could be reconciled.

Regardless of production network type, Wiendahl and Lutz (2002) stated that intensified cooperation between manufacturing companies leads to modified tasks for production planning and control.
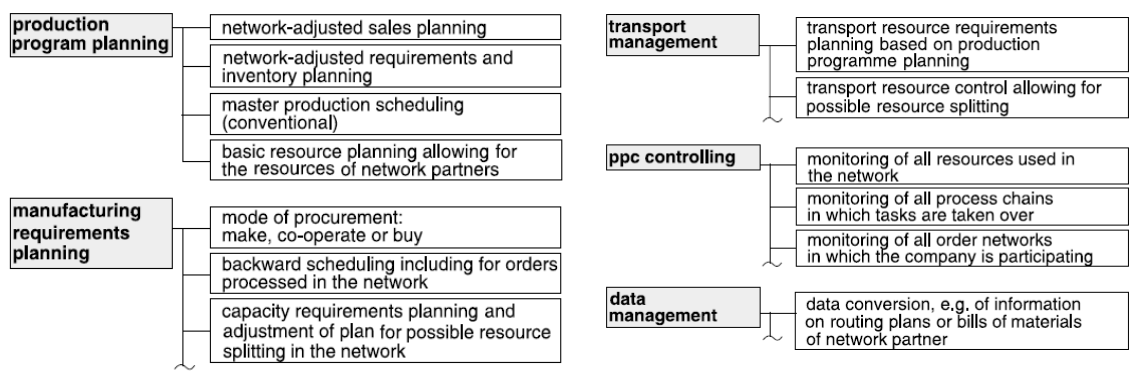

Fig. 1. Production planning and control functions in production network [adapted from 16]

Figure 1 shows how the core tasks of production planning and control (PPC) are oriented toward synchronization between network partners. Production program planning include synchronization between plants in the network, regarding sales, inventory and resource planning. Manufacturing requirements planning has to consider modified modes of planning for procurement, backward scheduling and capacity requirements. Thus, the collective functions of order coordination, inventory management and controlling will become more important for planning in networks than in conventional PPC environments, since every decision need to take to account complex interrelationships between processes. Control of plan in the network and planning for transportation plays significant role in the network planning. As it discussed by Kanyalkar and Adil [17] and Scholz-Reiter, Dashkowskiy [10] transport and distribution need to become an integral part of PPC processes in the network.

In general, PPC tasks in a production network are characterized by intensive communication between network partners and in broader perspective, with suppliers and customers. The goal is to get everyone in the production network into a common platform for logistics transactions and information systems [18]. This integration can result in significantly faster system responses to changes in marketplace events and patterns of demand. As a result, a 
highly organized network of complementary companies across the supply chain can rapidly build strategic effectiveness.

\section{$4 \quad$ Case study}

This section firstly describes the case company and its key network planning processes, and secondly summarizes the key insights from the case study with regards to the applicability of ERP for network planning.

\subsection{Introduction to the case company}

The case company is food producer with over 40 production facilities. The plants produce three main categories of products and the case study focuses on one of these. The products in this category are produced in three facilities, totaling over 100 product variants with varying production volumes. Although the three plants produce the same category of products, the variants are partially distributed among them and each facility is partly specialized for producing a set of variants. However, some variants are produced in all three plants. The company has strategically positioned the three facilities in different geographical positions in order to keep proximity to both suppliers and customers. Based on definition given in section 3 , the case company can be defined as intra-firm production network (one organization with multiple plants), with parallel structure.

The company uses a combination of centralized and decentralized PPC, and uses an ERP system for production planning. In addition, the company has recently started using specialized supply chain planning software for strategic planning and design of the production network.

\subsection{Production planning}

The company's main planning and control principle is make to stock (MTS) based on forecasts and inventory levels. The main argument for this is that in many cases the production lead time is longer than customer order lead time expectations. Therefore, not only the tactical production planning is based on forecasts, but also short term and tactical planning operations [19]. The planning and control process consists of both centralized and local planning performed by resources belonging to different functions. Below, the PPC processes are described using the framework in Erreur ! Source du renvoi introuvable.

Production program planning in ERP.

Production planning (including demand management, master production schedule, and rough cut resource planning) [20] is the responsibility of the supply chain management department and is performed both centrally and at the individual facilities. As mentioned, planning and control is based on forecasts. The central forecasting department updates weekly sales forecasts continuously at the stock keeping unit (SKU) level with a horizon of 104 weeks. The central planner performs the weekly production planning for all three facilities. The ERP system suggests a production plan for each facility based on the forecasts, and this is then manually adjusted by the central planner for main two reasons. Firstly, more up-to-date information about orders and changes in the market place needs to be incorporated into the forecast, and secondly, the central planner uses the forecast for subsequent weeks to bring production forward in order to level the production for each plant over the next two weeks. 
A key drawback of the company's ERP system is that it is not designed to automatically adjust the sale forecasts based on actual orders. In addition, since there is no possibility to have a view of all production plants at the same time, and due to high number of product types, it is difficult to analyze the effect of plan adjustments on performance criteria such as inventory level and capacity utilization.

\section{Manufacturing requirement planning in ERP.}

Replenishment planning (including detailed material and capacity planning) is also the responsibility of the supply chain management department and performed at both the central and facility level with a planning horizon of one day up to four weeks. The company's ERP system uses closed loop MRP which includes capacity requirement planning (CPR) for evaluating the consequences of the material plan on capacity.

Since ERP systems used by case company was not using advanced planning and scheduling (APS) extension, the material and production plans need several adjustments before they can be executed. The reason is that the ERP system does not have an over view of all three plants before planning, and therefore leveling of capacity has to be done for every plant, individually, without taking to account the effect of changes in order allocation, and capacity load of other plants. The problem is amplified when the capacity of the production system has high correlation with the skills and availability of human resources since these are variable and have a direct effect on the feasibility of the production plans. Further, the lack of coordinating functionality to support planning in a network of parallel production plants complicates the use of the ERP system for requirement planning.

\section{Transportation planning in ERP.}

The company's distribution division is responsible for transport scheduling, which involves planning of transport between facilities on a weekly horizon. The transportation plan is not only meant to plan distribution of finished goods based on customer orders, but also transportation between plants. Since the production plan is mainly based on forecasts, inter network transportation is important when actual demand exceeds available inventory volumes at each facility. Therefor planning of transport requirements depends on both customer orders and the central planner's allocation of orders to the individual plants.

\section{Production planning control in ERP.}

As it explained earlier case company uses combination of decentralized and centralized control principle, where in, detailed planning is done internally by individual network partners and the general planning (Production program planning) is performed at the network level. Using ERP system, the central planner have a good overview of resource used in the network, and can monitor production processes which are under process at each plant in the network, however any corrective action in the plan needs excessive communication between network partners and central planners.

\section{Data management.}

Since all plants in the production network are belong to one organization, ERP system gives good access to data for all members of the production network in the case company. 
Analysis

The previous section described some of the key production planning tasks in the case company's production network, including production program planning, manufacturing requirement planning and transportation management. Based on interviews and observation of the current situation in the case company, a number of insights on the effect of using an ERP system for network planning were generated.

\subsection{Production program planning}

The ERP system in the case company is not capable of distributing orders between network facilities and therefore a number of manual adjustments are needed before volumes are allocated to each plant. As a result, the ERP system does not provide any support in the optimization of order allocation to plants in the network based on available capacity, inventory status, or proximity to the customer.

\subsection{Manufacturing requirement planning}

The ERP system's functionality is limited in terms of taking into consideration detailed planning parameters from each facility in the network such as:

- Coordinating material plans between all facilities

- Coordinating capacity plans between all facilities

This means that the local planners at the individual facilities must make decisions based on their own experience and rules of thumb, without support from the ERP system. This includes daily schedules and personnel planning. Since the ERP system used by case company did not have advanced planning and scheduling (APS) extension [5] details on local personnel availability is not considered in the plan, therefore the system provides little or no support for short term planning for production operations that are human resource dependent [21].

\subsection{Transportation planning}

Although ERP system is used for distribution planning, however, internal transportation is not included in the planning phase as an option for resource splitting. That means, potentials of the network is not used in planning phase but considered in control of the plan as a potential for support in unscheduled events, reactively.

\subsection{Production planning control}

Although the control principle used by the case company gives a reasonable chance to all plants in the network to have a control over production processes, there is still strong arguments in the theory for applying fully centralized planning in production network [17, 22]. The applicability of ERP system in production networks under fully centralized control principle [15] need to be studied for the case company.

\subsection{Data management}

Being part of one organization and producing the same family of product in all three plants, and as a consequence using the same resources gives a good motive for plants in the network to share relevant data and ERP system showed to be effective in that regards.

The production network context can provide advantages in terms of using network partners for controlling and reducing the effects of demand uncertainty. However, the ERP system does not support internal distribution decisions in the network and such decisions therefore have to be made manually and require considerable communications between the facilities. 
Moreover, the ERP system was found to have limited flexibility to cope with unforeseen events in short terms plans caused by for instance changes in demand and machine breakdowns that affect capacity.

\section{Conclusion}

This paper used a case study to investigate the applicability of ERP systems for production planning in production networks. The conclusion is that the ERP system provides limited support for the major planning activities in the production network and prevents the company from fully exploiting the network setting.

The results obtained from this study may not be generalizable as findings are verified in only one case. However, we believe that the case company is not unique and that many other companies are also attempting to use their ERP systems to support planning across network facilities. Therefore, the results from our study may provide valuable insights for managers and executives on how the use of ERP systems for network planning may in fact limit the network's ability to reap the full benefits associated with planning across several facilities in a network.

The paper contributes to theory by highlighting that although ERP systems are not designed for planning in the network context, and despite the availability of advanced planning systems, in practice, companies are still trying to use their ERP systems to support their main planning processes. This provides good motivation for future research to find solutions and tools that can be used together with ERP systems to meet production network requirements and reap more benefits of the network context.

\section{Acknowledgment}

The research in this paper was financed by the Norman project (see www.sfinorman.no) and the Research Council of Norway.

\section{References}

1. Thoben, K.D. and H.S. Jagdev, Typological issues in enterprise networks. Production Planning \& Control, 2001. 12(5): p. 421-436.

2. Göttlich, S., M. Herty, and C. Ringhofer, Optimal Order and Distribution Strategies in Production Networks, in Decision Policies for Production Networks, D. Armbruster and K.G. Kempf, Editors. 2012, Springer London. p. 265-287.

3. Jagdev, H.S. and K.D. Thoben, Anatomy of enterprise collaborations. Production Planning \& Control, 2001. 12(5): p. 437-451.

4. Van Nieuwenhuyse, I., et al., Advanced resource planning as a decision support module for ERP. Computers in Industry, 2011. 62(1): p. 1-8.

5. Aslan, B., M. Stevenson, and L.C. Hendry, Enterprise Resource Planning systems: An assessment of applicability to Make-To-Order companies. Computers in Industry, 2012. 63(7): p. 692705 .

6. Yin, R.K., Case Study Research: Design and Methods. 2013: SAGE Publications.

7. Rudberg, M. and J. Olhager, Manufacturing networks and supply chains: an operations

8. Phillis, Y.A., H. D'Angelo, and G.C. Saussy, Analysis of Series-Parallel Production Networks without Buffers. Reliability, IEEE Transactions on, 1986. 35(2): p. 179-184.

9. Wiendahl, H.P., Load-oriented Manufacturing Control. 1995: Springer-Verlag. 
10. Scholz-Reiter, B., et al., Autonomous Decision Policies for Networks of Production Systems, in Decision Policies for Production Networks, D. Armbruster and K.G. Kempf, Editors. 2012, Springer London. p. 235-263.

11. Kopanos, G.M. and L. Puigjaner, Multi-Site Scheduling/Batching and Production Planning for Batch Process Industries, in Computer Aided Chemical Engineering, C.A.O.d.N. Rita Maria de Brito Alves and B. Evaristo Chalbaud, Editors. 2009, Elsevier. p. 2109-2114.

12. Guinet, A., Multi-site planning: A transshipment problem. International Journal of Production Economics, 2001. 74(1-3): p. 21-32.

13. Sheu, C., B. Chae, and C.-L. Yang, National differences and ERP implementation: issues and challenges. Omega, 2004. 32(5): p. 361-371.

14. Jacobs, F.R. and D.C. Whybark, Why ERP?: a primer on SAP implementation. 2000: Irwin/McGraw-Hill.

15. Markus, M.L., C. Tanis, and P.C.v. Fenema, Enterprise resource planning: multisite ERP implementations. Commun. ACM, 2000. 43(4): p. 42-46.

16. Wiendahl, H.P. and S. Lutz, Production in Networks. CIRP Annals - Manufacturing Technology, 2002. 51(2): p. 573-586.

17. Kanyalkar, A.P. and G.K. Adil, Aggregate and detailed production planning integrating procurement and distribution plans in a multi-site environment. International Journal of Production Research, 2007. 45(22): p. 5329-5353.

18. Kuehnle, H., A system of models contribution to production network (PN) theory. Journal of Intelligent Manufacturing, 2007. 18(5): p. 543-551.

19. Romsdal, A., Food Supply Chains; concept, frameworks and guidlines for differentiated production planning and control, N.U.o.S.a. Technology, Editor. 2013.

20. Vollmann, T., MANUFACTURING PLANNING AND CONTROL SYSTEMS FOR SUPPLY CHAIN MANAGEMENT: The Definitive Guide for Professionals. 2005: McGraw-Hill Education.

21. Dreyer, H.C., et al., Global supply chain control systems: a conceptual framework for the global control centre. Production Planning \& Control, 2009. 20(2): p. 147-157.

22. Scholz-Reiter, B., C. Meinecke, and D. Rippel, Network Collaboration, in Intelligent Nonhierarchical Manufacturing Networks. 2013, John Wiley \& Sons, Inc. p. 169-184. 